\title{
Editorial
}

\section{Promoting Advance Directive Discussions}

\author{
James S. Powers, MD ${ }^{1,2^{*}}$ \\ 'Tennessee Valley Healthcare System, Geriatric Research Education and Clinical Center, Nashville, Tennessee 37232, USA \\ ${ }^{2}$ Vanderbilt University School of Medicine, Nashville, Tennessee, USA \\ "Corresponding author \\ James S. Powers, MD \\ Clinical Associate Director, Tennessee Valley Healthcare System, Geriatric Research Education and Clinical Center,Vanderbilt University School of \\ Medicine, Nashville, Tennessee 37232, USA;Tel.615-343-6726; Fax.615-322-1754; E-mail: James.powers@vanderbilt.edu
}

\section{Article information}

Received: November 22 ${ }^{\text {nd }}$, 2020; Accepted: November 25 ${ }^{\text {th }}$, 2020; Published: December I ${ }^{\text {st }}, 2020$

\section{Cite this article}

Powers JS. Promoting advance directive discussions. Palliat Med Hosp Care Open J. 2020; 6(2): e3. doi: 10.17/40/PMHCOJ-6-e0I0

\begin{abstract}
A dvance care planning (ACP) which includes a discussion of Agoals of care and preferences about future care improves patient-centered care at the end-of-life. However, completion of ACP remains low with an estimated $36.7 \%$ of adults having completed an advance directive in the United States ${ }^{1}$ and this number is lower in many other societies worldwide. Social stigma, personal difficulty accepting the finality of life, and agism all contribute to avoidance of discussions of end-of-life care. The topic of ACP is an intensely personal one, and optimally a longitudinal communication-based conversation between individuals, families, and trusted healthcare professionals. In the absence of ACP urgent discussions necessitated by medical crises, while necessary, are often traumatic and may limit involvement of the affected individual and place increased burden on the surrogate decision maker.
\end{abstract}

Many models to promote ACP are in common use, including education on the importance of advance directives for primary care providers, clinical prompting at the point of patient care, embedding palliative care trained clinicians in chronic disease and oncology clinics, and inquiring about the presence of advance directives on presentation at healthcare facilities. More recent models include targeted outreach by providers utilizing a risk stratification tool to identify high-risk patients for ACP completion, ${ }^{2}$ outreach by non-provider healthcare workers, ${ }^{3}$ and evaluating the effectiveness of billable ACP discussions to enhance form-based ACP documentation in the healthcare record. ${ }^{4}$

It is time to reimagine the approach to ACP and create a cultural shift in society to enhance the discourse on end-of-life care, taking a public health approach. ${ }^{5}$ One model may be to integrate consideration of ACP into regular benefits "check-ups" among employed individuals during enrollment and open season periods. Enhanced discussion and completion of advance directives among employed individuals may encourage intergenerational conversations about end-of-life care with other family members. It may also lead to discussions with trusted healthcare providers and improved documentation in healthcare records. Large employers especially have the potential to reach numerous individuals and to help normalize the conversation on end-of-life care. This can benefit all of society, demystify and reduce the stigma related to ACP, and help avoid emergency ACP.

\section{REFERENCES |}

1. Yadav KN, Gabler NB, Cooney E, Kent S, Kim J, Herbst N, et al. Approximately one in three US adults completes any type of advance directive for end-of-life care. Health Aff (Millwood). 2017; 36(7): 1244-1251. doi: 10.1377/hlthaff.2017.0175

2. Powers JS, Abraham L. Outpatient-focused advance care planning: Telehealth consultation for geriatric primary care patients. Palliat Med Hosp Care Open J. 2019; 5(2): 23-26. doi: 10.17140/PMHCOJ-5-133

3. Patel MI, Sundaram V, Desai M, Periyakoil VS, Kahn JS, Bhattacharya J, et al. Effect of a lay health worker intervention on goals-of-care documentation and on health care use, costs, and satisfaction among patients with cancer: A randomized clinical trial. JAMA Oncol. 2018; 4(10): 1359-1366. doi: 10.1001/jamaoncol.2018.2446.1934

4. Gupta A, Jin G, Reich A, Prigerson HG, Ladin K, Kim D, et al. Association of billed advance care planning with end-of-life care intensity for 2017 medicare decedents. J Am Geriatr Soc. 2020. doi: 10.1111 /ggs.16683

5. Abel J, Kellehear A. Palliative care reimagined: A needed shift. BMJ Support Palliat Care. 2016; 6(1): 21-26. doi: 10.1136/bmjspcare-2015-001009 